\title{
R-factor Gene Expression in Gram-negative Bacteria
}

\author{
By J. T. SMITH \\ Department of Pharmaceutics, School of Pharmacy, Brunswick Square, \\ London, W.C. I
}

(Accepted for publication 3I August 1968)

SUMMARY

Methods by which the R-factor 1818 was transferred from Escherichia coli KI 2 to different species of Gram-negative bacteria are described. Possession of 1818 resulted in the production of similar amounts of $R$-factor specific penicillinase per organism in E. coli, Serratia marcescens, Alkalescens sp. and Aerobacter aerogenes. The Aerobacter strain produced additionally a 'chromosomal' penicillinase which had no influence on the level of R-factor enzyme.

Two different strains of Proteus mirabilis containing R-factor I818 produced only about $\frac{1}{20}$ th of this penicillinase activity per bacterium Two further R-factors 7268 and TEM also specifying penicillinase were introduced into the $P$. mirabilis strains and enzyme activities per bacterium of about $\frac{1}{20}$ th and $1 \frac{1}{0} 0$ th, respectively, were obtained compared with those in $E$. coli. All organisms in cultures of $\boldsymbol{P}$. mirabilis exhibited properties of R-factor possession and thus R-factor instability cannot explain these results. It would seem that the phenotypic expression of $\mathbf{R}$-factor penicillinase genes is impaired in this species.

\section{INTRODUCTION}

It has been shown that $F$ prime $\left(F^{\prime}\right)$ episomes can be detected in Proteus and Serratia strains due to the presence of a physically distinguishable satellite DNA fraction of Escherichia base composition (Marmur et al. 196I ; Falkow, Wohlhieter, Citarella \& Baron, 1964). Similar satellite bands have been observed when R-factors are present in Proteus and Serratia (Falkow, Wohlhieter, Citarella \& Baron, 1963; Falkow, Citarella, Wohlhieter \& Watanabe, 1966; Rownd, Nakaya \& Nakamura, 1966). Calculations based on the relative amounts of DNA in the main and satellite bands have indicated that approximately one R-factor exists per bacterial chromosome in Escherichia and Serratia, whereas there are about ten copies per Proteus mirabilis chromosome (Rownd et al. 1966). On the other hand, Falkow et al. (I964) have shown that $F$-lac $\beta$-galactosidase synthesis in $P$. mirabilis is constitutive at about $25 \%$ of the level of that of the same gene on the chromosome of fully induced Escherichia coli. However, it could be argued that comparisons between the products of a gene on an episome with those of a chromosomal gene are not valid. Nevertheless, Colby \& Hu. (1968) have extended this work to compare levels of $\beta$-galactosidase produced by episomal lac genes in $E$. coli and $P$. mirabilis and obtained broadly similar results. They conclude that there is an anomalous regulation in Proteus which may be attributed to the cytoplasmic environment of the F-lac episome.

The expression of penicillin resistance carried by $\mathrm{R}$-factors is by the production of penicillinase by the cells harbouring such episomes (Anderson \& Datta, 1965; Ander- 
son \& Lewis, 1965). This communication concerns the introduction of penicillinase specifying R-factors into Escherichia coli, Serratia marcescens, Aerobacter aerogenes, Alkalescens sp. and Proteus mirabilis using an E. coli donor. Subsequent investigations of the penicillinase levels in the resultant $\mathrm{R}$-factor containing bacteria show that Escherichia, Serratia, Aerobacter and Alkalescens express a similar level of R-factor gene activity per bacterium. However, two strains of $P$. mirabilis, including that of Rownd et al. (1966), were found to exhibit much less R-factor gene activity per organism than the other species and with R-factor TEM the level was less than I \%. Kontomichalou (1967) also found that $P$. mirabilis produced less $R$-factor penicillinase than $E$. coli but she observed much higher levels than reported here since all her Rfactors including TEM produced about one-third of the $E$. coli level. These results at first sight do not agree with the work of Rownd et al. (1966) as one would expect that, if there are as many as more than Io copies of the R-factor per $\boldsymbol{P}$. mirabilis organism, higher enzyme levels would be found. It is possible, however, to resolve these differences by postulating extreme impairment of $\mathrm{R}$-factor gene function in $P$. mirabilis.

\section{METHODS}

Bacterial strains. The strains of Escherichia coli KI2, Serratia marcescens, Aerobacter aerogenes, Alkalescens sp. and Proteus mirabilis that were used in this study are listed in Table $I$.

R-factors. All R-factors were kindly supplied by Dr Naomi Datta; they were carried by the same host strain, Escherichia coli $\mathrm{Kr} 2$, and are listed in Table 2.

Media. Davis \& Mingioli (1950) liquid and solid minimal medium (DM) was prepared as described by Smith (1967). Oxoid Nutrient Broth no. 2 and MacConkey agar were supplied by Oxoid Ltd., Southwark Bridge Road, London, S.E. I.

Drugs and chemicals. Streptomycin sulphate, tetracycline hydrochloride, sodium ampicillin and sodium sulphadiazine were bought commercially as sterile products. These were weighed and dissolved in sterile distilled water using aseptic procedures. Amino acids, vitamins and other reagents were purchased from L. Light and Company Limited, Colnbrook, Buckinghamshire.

Supplements. Amino acid supplements with the exception of methionine were dissolved in distilled water, adjusted to $\mathrm{pH} 7 \cdot 4$ with $\mathrm{NaOH}$, autoclaved and added singly at a final concentration of $40 \mu \mathrm{g}$. of the $\mathrm{L}$ isomer $/ \mathrm{ml}$. Nicotinic acid was used at a final concentration of $5 \mu \mathrm{g}$. $/ \mathrm{ml}$. A great deal of trouble was experienced with the growth of strain KI2 on minimal media and this was finally traced to heat sterilization of methionine. It was found that only freshly prepared filter-sterilized DL-methionine ( $50 \mu \mathrm{g} . / \mathrm{ml}$.) gave satisfactory viable counts with this organism as judged by comparison with growth on nutrient agar. 


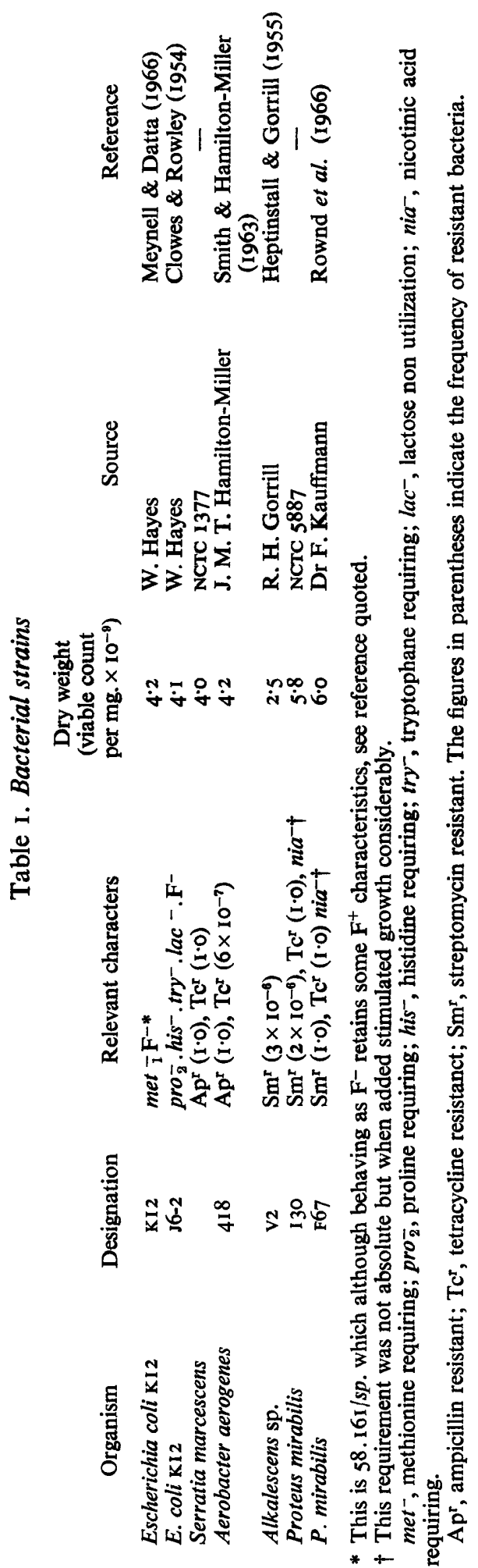




\section{Transfer of $R$-factor 1818}

An incubation temperature of $37^{\circ}$ was used throughout this work. Overnight broth cultures of bacteria were used. Donor culture $(0 \cdot \mathrm{I} \mathrm{ml}$.) was mixed with $\mathrm{I} \cdot 0 \mathrm{ml}$. of recipient culture and $4.9 \mathrm{ml}$. of warm fresh broth and incubation continued for $6 \mathrm{hr}$. To wash the organisms $20 \mathrm{ml}$. of DM medium without glucose (DM buffer) were then added and the mixture centrifuged, the supernatant discarded and the pellet reconstituted in $6 \mathrm{ml}$. of DM buffer with the aid of a Vortex junior mixer. These steps were necessary to exhaust the mixed culture of nutrients, which could otherwise be carried over on to the selective media and allow growth of the donor strain.

Table 2.

R-factor
I818
7268
TEM

Species in which isolated
S. typhimurium
S. paratyphi $B$
E. coli

Resistances
Ap Sm Su Tc
Ap (Sm*) Su Cm Km
Ap Sm

These R-factors were originally described by Datta \& Kontomichalou (1965). Subsequently 1818 and 7268 have been designated R46 and RI respectively (Meynell \& Datta 1966 ).

Ap, ampicillin; $\mathrm{Sm}$, streptomycin; $\mathrm{Su}$, sulphonamide; Tc, tetracycline; $\mathrm{Cm}$, chloramphenicol; $\mathrm{Km}$, Kanamycin; *low level of resistance only.

Serial decimal dilutions of 'washed' mixed culture were made in DM buffer and $0.1 \mathrm{ml}$. amounts plated and spread with a glass spreader on selective media supplemented for the recipient only and containing antibiotic sufficient to inhibit growth of the recipient lacking the $\mathbf{R}$-factor. Controls were made using donor and recipient bacteria cultured separately to ensure that: $(a)$ no growth of donor bacteria could occur, and $(b)$ no growth of the recipient strains could occur unless they possessed the $\mathrm{R}$-factor. To investigate the inoculum size effect further controls were made using donor bacteria killed by ultraviolet irradiation in DM buffer mixed with a similar number of viable recipient bacteria. In addition plates spread with viable donor bacteria were overlaid with an Oxoid cellulose acetate filter membrane which was then spread with a similar number of viable recipient bacteria. These controls showed that at dilutions $<1 \mathrm{IO}^{-2}$ Io $\mu \mathrm{g}$. $/ \mathrm{ml}$. Streptomycin (Sm) or Tetracycline (Tc) was necessary to prevent growth of recipient bacteria without the R-factor and that neither Sulphonamide (Su) nor Ampicillin (Ap) could be used reliably at these dilutions. Further tests showed that significant Ap destruction had occurred after 3 days incubation of plates spread with such numbers of donor bacteria. At dilutions $>1 \mathrm{IO}^{-2}$ it was found that optimum recovery of all 1818 recipients was obtained using $\mathrm{Sm}, \mathrm{Tc}, \mathrm{Ap}$ or $\mathrm{Su}$ at a concentration of $5 \mu \mathrm{g} . / \mathrm{ml}$.

In order to estimate the number of donor and recipient bacteria dilutions were also spread on MacConkey agar. It was found that colonies of all the mixtures used could be differentiated by eye this way. In addition, as a check, separate platings were made on DM media appropriately supplemented or otherwise manipulated to allow the separate growth of the donor or recipient strain. With the Proteus strains it was found that MacConkey agar was extremely inhibitory since less than I \% formed colonies as judged by total counts. However, complete recovery of these bacteria was observed using DM agar supplemented with nicotinic acid. 
Incubation of all plates was made for up to 3 days. Selected colonies were purified by three successive streakings on the same selective media before the strains were regarded as pure. In addition streakings were made on nutrient and MacConkey agar to check that no donor organisms persisted and on media containing Sm, Su, Ap or Tc to ensure that all resistances had been transferred.

\section{Estimation of penicillinase}

Cultivation and counting. Cultures were grown overnight at $37^{\circ}$ in $50 \mathrm{ml}$. amounts of nutrient broth in $100 \mathrm{ml}$. bottles. Viable counts were made by dilution in nutrient broth at $37^{\circ}$ and spread on nutrient agar at $37^{\circ}$. The Proteus strains, were counted on DM agar supplemented with nicotinic acid which prevented spreading of the colonies. In order to test whether segregation of bacteria lacking the R-factor occurred counts were also made using selective media which was designed to prevent completely growth of recipient bacteria lacking the R-factor but allow complete growth of the R-factor carrying bacteria. The antibiotics used were $\mathrm{Sm}$, Tc or Su at a concentration of $5 \mu \mathrm{g}$. $/ \mathrm{ml}$. or Ap $2 \mu \mathrm{g}$. $/ \mathrm{ml}$. in DM agar where appropriate with respect to the innate sensitivity of the host strain. At least two antibiotics were used to check each strain. With all the strains studied such segregation was insignificant $(<\mathrm{I} \%)$ with the exception of Serratia marcescens/1818, which segregated organisms lacking the R-factor at a frequency of about $8 \%$. Such segregants were excluded from calculations of penicillinase activity.

Bacterial cultures were centrifuged and the viable count of the supernatant fluid estimated. This was subtracted from the culture count and the resulting number used in calculations for penicillinase activity. These procedures were found to be necessary since, depending on the strain studied, different fractions of the bacteria were left in the supernatant fluid and resuspension of the pellet in phosphate buffer killed a fraction of the bacteria it contained.

Penicillinase assay. The pellet was resuspended in $5 \mathrm{ml} .25$ mM-sodium phosphate buffer pH 7.4 and cooled to $4^{\circ}$. To remove crypticity (Cohen \& Monod, 1957) the suspension was treated in an MSE ultrasonic disintegrator at $\mathrm{I} \cdot 5 \mathrm{~A}$. and $4^{\circ}$ for $4 \mathrm{~min}$. Suitable dilutions of the disrupted bacteria were made in $25 \mathrm{~mm}$-sodium phosphate buffer $\mathrm{pH} 7.4$ at $4^{\circ}$ and substrate added to a concentration of $5 \mathrm{~mm}$. The reactionmixture was warmed at $30^{\circ}$ in a water bath and the amount of penicillin remaining determined by the hydroxylamine assay as described by Smith (1963). These precautions were necessary as it was found that, irrespective of the host strain, the enzyme produced by the $\mathrm{R}$-factor $18 \mathrm{r} 8$ was thermolabile at temperatures above $33^{\circ}$ especially when dilute. This thermolability was decreased when the enzyme was protected by substrate. Hence to avoid thermal inactivation completely substrate was added before the reaction mixture was incubated and an assay temperature of $30^{\circ}$ was used.

The destruction of penicillins was followed by using substrate concentrations sufficient to saturate the enzyme. Control tests showed that, with all strains studied, the penicillinase activity was largely intracellular since $>95 \%$ of the total penicillinase activity of a culture could be recovered in the disrupted pellet. Results were expressed in $\mu$ mole of substrate destroyed per min. which are units recommended by the International Commission on Enzymes (Thompson, 1962). 


\section{RESULTS \\ Transfer of $R$-factor 1818}

With Escherichia coli J6-2 recipient. The results (Table 3, Expt. I) show that the transfer frequency is similar irrespective of the antibiotic used and probably reflects the simultaneous transmission of all four resistances. Furthermore, the penicillinase activity of strain $\mathrm{J6-2}$ ( $18 \mathrm{I} 8$ ) isolated independently on media containing each antibiotic was found to be similar to that of strain KI2 (I8I8). Indeed when J6-2 (I8I8) was used as donor and $\mathrm{KI2}$ as recipient similar findings as regards transfer frequency and penicillinase activity were made.

Table 3. Transfer of $R$-factor $I 8 I 8$ to different species of bacteria

\begin{tabular}{|c|c|c|c|c|}
\hline \multirow{3}{*}{$\begin{array}{c}\text { Expt. no. } \\
\text { I }\end{array}$} & \multirow{3}{*}{$\begin{array}{c}\text { Recipient } \\
\text { Escherichia coli } \mathrm{J6-2}\end{array}$} & \multirow{3}{*}{$\begin{array}{c}\text { Selective } \\
\text { agent } \\
\text { Tc } \\
\text { Ap } \\
\text { Sm } \\
\text { Su }\end{array}$} & \multicolumn{2}{|c|}{$\begin{array}{c}\text { Frequency of transfer per } \\
\text { bacterium }\end{array}$} \\
\hline & & & Donor & Recipient \\
\hline & & & $\begin{array}{l}1.3 \times 10^{-2} \\
1.4 \times 10^{-2} \\
1.5 \times 10^{-2} \\
1.6 \times 10^{-2}\end{array}$ & $\begin{array}{l}8.9 \times 10^{-3} \\
9.7 \times 10^{-8} \\
1.0 \times 10^{-2} \\
1 \cdot 1 \times 10^{-2}\end{array}$ \\
\hline 2 & Serratia marcescens & $\mathrm{Sm}$ & $2.0 \times 10^{-3 *}$ & $1.4 \times 10^{-5}$ \\
\hline 3 & P. mirabilis $\mathbf{F 6 7}$ & $\begin{array}{l}\text { Sm } \\
\text { Su } \\
\text { Ap } \\
\text { Su } \\
\text { Ap }\end{array}$ & $\begin{array}{l}1.4 \times 10^{-1} \\
1.7 \times 10^{-1} \\
1.6 \times 10^{-1} \\
3.3 \times 10^{-1} \\
2.9 \times 10^{-1}\end{array}$ & $\begin{array}{l}3.3 \times 10^{-2} \\
4.0 \times 10^{-2} \\
3.8 \times 10^{-2} \\
9.2 \times 10^{-2} \\
8.1 \times 10^{-2}\end{array}$ \\
\hline 4 & Alkalescens sp. v2 & Tc & $3.0 \times 10^{-9}$ & $1 \cdot 3 \times 10^{-8}$ \\
\hline 5 & Aerobacter aerogenes 418 & Tc \& Sm & $1 \cdot 9 \times 10^{-6}$ & $3.0 \times 10^{-7}$ \\
\hline
\end{tabular}

With Serratia marcescens recipient. When the transfer of R-factor to Serratia marcescens was studied it was found that the KI2 donor was rapidly killed, presumably due to a phage or colicin carried by the $S$. marcescens, but nevertheless R-factor transfer was observed (Table 3, Expt. 2). A similar phenomenon has been reported by Watanabe (I963).

With Proteus mirabilis recipients. The transfer of R-factor 1818 from KI2 (I818) to Proteus mirabilis strains 130 and F67 occurred at high frequency which was similar irrespective of the drug used to select $P$. mirabilis (1818) (Table 3, Expt. 3).

With Alkalescens sp. strain $V 2$ recipient. Numerous unsuccessful attempts were made to transfer from KI2 (18I8) to V2 by using nutrient broth cultures. The recipient is very mucoid which is possibly the reason why its dry weight is highest of all strains used here (Table I). It was thought that large amounts of capsular material could interfere with conjugation. Since growth of this organism on DM agar was much less mucoid it seemed possible that $\mathrm{R}$-factor transfer might occur using DM liquid medium. When DM-grown donor and recipient bacteria were mixed and culture continued in DM medium R-factor transfer was observed, albeit at very low rates (see Table 3, Expt. 4), using Tc to select for v2 (I8I8). Streptomycin (Sm) was not suitable since the 
natural mutation rate of V2 was higher than the transfer rate (see Table I) and neither Ap nor Su were suitable due to reasons stated in the methods.

With Aerobacter aerogenes 418 recipient. This recipient behaved like Alkalescens sp. strain $\mathbf{V} 2$ in that, despite repeated attempts, transfer was not observed in nutrient broth. Since this is also a mucoid strain attempts were made to obtain transfer using DM medium and Sm as selective agent, again without success. Ap could not be used as the recipient strain produces penicillinase (Smith \& Hamilton-Miller, 1963) and Su was also unsuitable (see methods). Tc suffered from the defect that the natural mutation rate of $4 \mathrm{I} 8$ to $\mathrm{Tc}$ resistance was significant (see Table $\mathrm{I}$ ) and precluded its use as a direct selective agent under conditions of low frequency transfer. However, when DM grown bacteria were cultured together in DM medium and plated on Tc it was found that colonies of $4 \mathrm{I} 8$ (I8I8) could be differentiated from those of $4 \mathrm{I} 8$. Tc $\mathrm{T}^{\mathrm{r}}$ by replication on $\mathrm{Sm}$ I0 $\mu \mathrm{g} . / \mathrm{ml}$, which selected for R-factor containing colonies. Thus transfer was achieved and the frequencies are shown in Table 3, Expt. 5. It is unknown why Sm failed to isolate this organism directly after mixed culture; subsequent investigation showed that resistance to $\mathrm{Sm}$ as well as resistance to the other three drugs was present in $4 \mathrm{I} 8$ (I8I8). Generally $\mathrm{Sm}^{\mathrm{r}}$ is more rapidly expressed when the allele is on a R-factor in comparison to a chromosomal location but wide variations in $\mathrm{R}$-factor $\mathrm{Sm}^{\mathrm{r}}$ expression do occur (Watanabe, I963) and it is possible that there is an abnormally long segregation lag in the Aerobacter recipient.

\section{Penicillinase activities of bacteria}

The substrate profile of the penicillinase activity of R-factor 18 I 8 has been published by Datta \& Kontomichalou (1965). In addition to the substrates studied by these authors it was found that oxacillin was very rapidly hydrolysed by this enzyme (J. M. T. Hamilton-Miller, personal communication). Therefore when the penicillinase activity of the strains studied here was investigated both oxacillin and benzylpenicillin were used as substrates. In addition, oxacillin was particularly useful as a sensitive index of R-factor 1818 penicillinase activity since most if not all other penicillinases studied do not significantly hydrolyse this substrate (Smith \& Hamilton-Miller, 1963). As the number of organisms studied here was too large to investigate simultaneously with accuracy each separate experiment was conducted using J6-2 (1818) and KI2 (18I8) as internal controls. All species were investigated with and without the R-factor. However, it was found that, with the exception of Aerobacter aerogenes 4I8, all strains lacking the $\mathrm{R}$-factor were penicillinase-negative or produced insignificantly low amounts of penicillinase. It is interesting that the penicillinase produced by 418 does not hydrolyse oxacillin, whereas that of $4 \mathrm{I} 8$ (I8I8) does (Table 4). Both enzymes, however, hydrolyse benzylpenicillin. The activity of 418 (I8I8) on benzylpenicillin was 49.6 milli units, whereas with 418 it was 12.6 milli units. The difference $(37 \cdot 0)$ is theoretically the benzylpenicillin activity due to the R-factor enzyme and agrees well with the activity of the Escherichia coli controls. Since 418 penicillinase does not attack oxacillin the penicillinase activity of 418 (I8I8) on oxacillin should reflect its $\mathrm{R}$-factor penicillinase alone and this was similar to the activities of the $E$. coli controls. Furthermore, the oxacillin: benzylpenicillin ratio $236 \cdot 3: 37 \cdot 0=6 \cdot 4$ agrees reasonably with the ratios obtained with all other $\mathrm{R}$-factor containing organisms.

With this consideration in mind it can be seen (Table 4) that all strains which possess R-factor 1818, with the exception of Proteus mirabilis strains 130 (1818), and F67 (1818), 

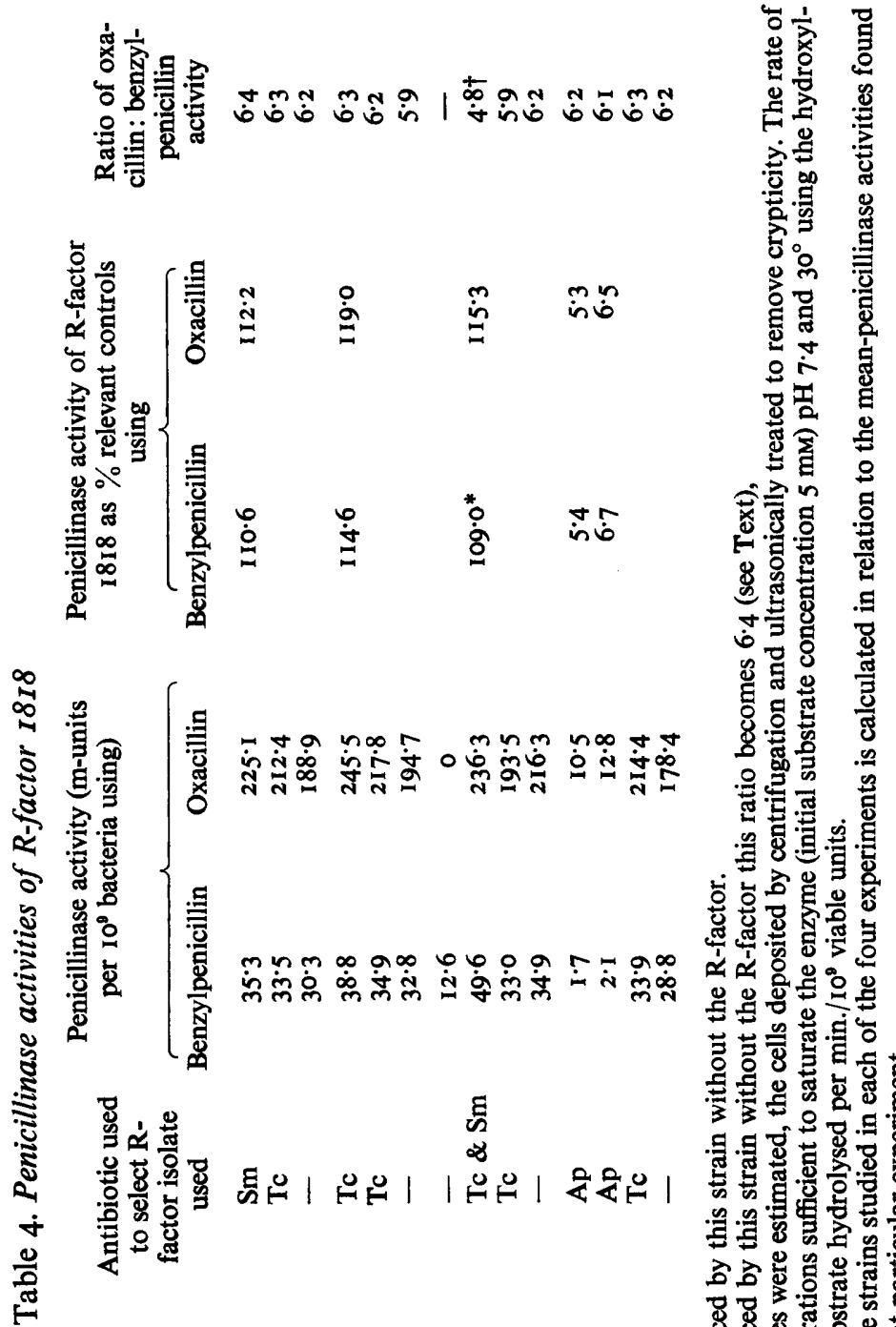

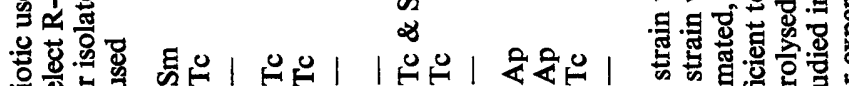

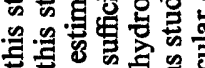

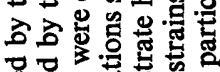

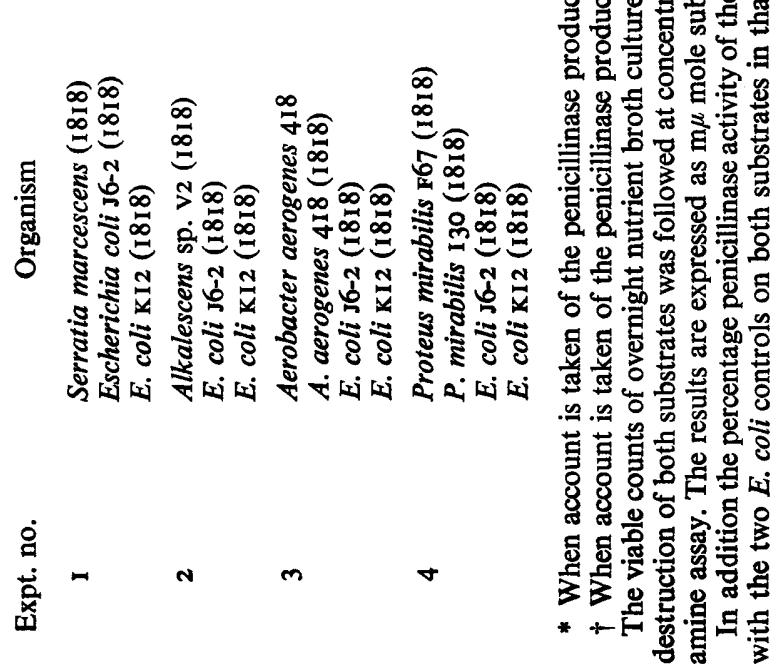


have penicillinase activities similar to those of the two Escherichia coli controls. The $P$. mirabilis, (1818) strains, make much less penicillinase (about $\frac{1}{20}$ th) than all the other strains studied here. Rownd et al. (I966) presented evidence showing that $P$. mirabilis F67 contained ro times as much R-factor satellite DNA as $E$. coli $\mathrm{KI} 2$ and if this is applicable here it would be expected that the $P$. mirabilis, (I8I8) strains, would make more, rather than less, penicillinase than $E$. coli KI2 (1818). Consequently further investigations were made into the penicillinase activity of the two $P$. mirabilis strains studied here. These included a careful examination into the amount of enzyme produced (a) extracellularly, $(b)$ by log. phase cultures, $(c)$ by I30 (I8I8) and F67 (I8I8) isolated on $\mathrm{Su}$ and 130 (1818) isolated on $\mathrm{Sm}$, and $(d)$ by bacteria cultured in DM medium. In no case was any discrepancy noted which could be used to explain the low penicillinase activity of these Proteus strains.

Tests were done to see if there was any synergism or antagonism in mixtures of crude enzyme preparations from Escherichia coli, (1818), and Proteus mirabilis, 1818, and in no case was any effect other than additive observed. Thus $P$. mirabilis cell sap does not contain any inhibitor of the R-factor penicillinase nor does the cell sap of $E$. coli contain any stimulatory factor for the R-factor penicillinase from $P$. mirabilis. Furthermore, although the dry weights of Proteus strains were about $33 \%$ lower than those of E. coli, Aerobacter aerogenes and Serratia (Table I) this was not sufficient to account for the difference in penicillinase levels.

Table 5. Penicillinase activity of 3 R-factors in Proteus mirabilis

\begin{tabular}{|c|c|c|c|c|}
\hline Organism & Strain no. & R-factor & $\begin{array}{l}\text { Penicillinase activity } \\
\text { using benzyl- } \\
\text { penicillin substrate } \\
\text { (m-units } / 1^{\circ} \\
\text { bacteria) }\end{array}$ & $\begin{array}{c}\text { Percentage peni- } \\
\text { cillinase activity } \\
\text { compared with } \\
\text { same R-factor in } \\
\text { E. coli } \mathrm{K} \text { I2 }\end{array}$ \\
\hline $\begin{array}{l}\text { Proteus mirabilis } \\
\text { P. mirabilis } \\
\text { Escherichia coli }\end{array}$ & 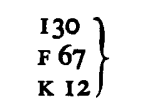 & (TEM) & $\left\{\begin{array}{r}7 \cdot 8 \\
7 \cdot 3 \\
907 \cdot 3\end{array}\right.$ & $\begin{array}{c}0.8 \\
0.9 \\
100\end{array}$ \\
\hline $\begin{array}{l}\text { P. mirabilis } \\
\text { P. mirabilis } \\
\text { E. coli }\end{array}$ & $\left.\begin{array}{l}\begin{array}{l}130 \\
F\end{array} 67 \\
K \quad 12\end{array}\right\}$ & (7268) & $\left\{\begin{array}{r}9 \cdot 0 \\
8 \cdot 9 \\
124 \cdot 9\end{array}\right.$ & $\begin{array}{c}7 \cdot 2 \\
7 \cdot 1 \\
100\end{array}$ \\
\hline $\begin{array}{l}\text { P. mirabilis } \\
P . \text { mirabilis } \\
\text { E. coli }\end{array}$ & 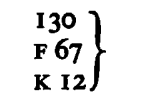 & $(1818)^{*}$ & $\left\{\begin{array}{r}2 \cdot I \\
I \cdot 7 \\
28 \cdot 8\end{array}\right.$ & $\begin{array}{r}6 \cdot 7 \\
5 \cdot 4 \\
100\end{array}$ \\
\hline
\end{tabular}

* Data taken from Table 4 for the sake of comparison.

The viable counts of overnight broth cultures were estimated, the cells deposited by centrifugation and ultrasonically treated to remove crypticity. The rate of destruction of benzylpenicillin was followed at concentrations sufficient to saturate the enzyme (initial concentration $5 \mathrm{mM}$ ) $\mathrm{pH} 7.4$ and $30^{\circ}$ using the hydroxylamine assay. The results are expressed as $m \mu$ mole of benzylpenicillin hydrolysed per.min. $/ 10^{\circ}$ viable units.

Since it was possible that these results could be explained by $R$-factor modification in the Proteus strains it was transferred from them to Escherichia coli KI 2 which was then tested for penicillinase production and a level similar to that produced by the original KI2 (I8I8) donor was detected. These results indicate that, at least as regards the penicillinase gene, no alteration to the $R$-factor had occurred as a result of its transfer into and out of Proteus mirabilis. Kontomichalou (1967) has also reported this finding. 


\section{Investigation of R-factors TEM and 7268 in Proteus mirabilis strains 130 and $F 67$}

Since the substrate specificity of the penicillinase of $R$-factor 1818 was found to be unlike that of any penicillinase studied in this laboratory and its thermolability was also unusual it was thought possible that other $\mathbf{R}$-factor penicillinases may behave differently in Proteus mirabilis. The penicillinases specified by R-factors TEM and 7268 have been stated (Datta \& Kontomichalou, 1965) to be similar to those produced by Aerobacter strains (Smith \& Hamilton-Miller, 1963). Accordingly, these were transferred from a $\mathrm{KI} 2$ donor using Ap ro $\mu \mathrm{g} . / \mathrm{ml}$. as selection for P. mirabilis (TEM) and $P$. mirabilis. (7268). The penicillinase activities (Table 5) are interesting in that by comparison with the corresponding $\mathrm{Kr} 2$ strain the level due to R-factor 7268 in either strain of Proteus is similar to that produced by R-factor 1818 (about $\frac{1}{20}$ th). The amount of enzyme produced by R-factor TEM is even more depressed as 130 (TEM) and F67 (TEM) produced less than I \% of the penicillinase activity of KI2 (TEM). Thus two different strains of $\boldsymbol{P}$. mirabilis containing three different $\mathrm{R}$-factors produce much less penicillinase than the corresponding Escherichia coli KI2 hosts.

\section{DISCUSSION}

When the R-factor 1818 was introduced into Escherichia, Serratia, Aerobacter and Alkalescens strains a similar degree of $\mathbf{R}$-factor specific penicillinase was produced. It is tempting to assume that the gene dosage effect (Jacob, Schaeffer \& Wollman, I960) is applicable to these four species. Conclusions drawn from this effect have been criticized (Jacob, Brenner \& Cuzin, 1963) on the grounds that Jacob \& Monod (I96I) found that $\beta$-galactosidase produced by a F-lac episome was 2.5 to 3 times more than that produced by normal haploid bacteria where the lac gene occupied a chromosomal position. Calculations by Yoshikawa \& Sueoka (1963) have shown that this difference may be attributed, not to a larger number of episomal genes, but to the likely possibility that episomal replication is completed long before that of the bacterial chromosome. However, the studies here have been with episomal genes only and no comparison has been drawn with levels of enzyme produced by the same gene in a chromosomal location. Another factor is that if a gene is subject to regulation it may be regulated differently in different cytoplasmic environments as, noted by Colby \& $\mathrm{Hu}$ (1968). However, this criticism does not apply here as preliminary work indicates that all these bacterial species were constitutive as regards their penicillinase. Indeed, the same applies to the penicillinase produced by chromosomal genes in many species of Gram-negative bacteria (Smith \& Hamilton-Miller, 1963). However, to prove gene dosage it will be necessary to estimate directly the amount of genetic material attributable to the R-factor in the species studied here and this project is being considered. It should be noted that experiments along these lines have been done with Escherichia and Serratia by Rownd et al. (1966), who found similar quantities of R-factor specific satellite DNA in these two species.

The extremely low level of R-factor penicillinase detected in Proteus mirabilis is difficult to explain. It would seem that since every organism can grow on antibiotic concentrations sufficient to inhibit completely the growth of bacteria lacking $R$-factor there must be at least one R-factor in each Proteus organism. Moreover, if the results of Rownd et al. (1966) are applicable here it is possible that $P$. mirabilis possesses 
about ten R-factor copies per bacterium and it seems improbable that gene dosage is applicable to this species. Kontomichalou (1967) also found that $P$. mirabilis produced less R-factor penicillinase than Escherichia coli. However, in relation to the E. coli level all her R-factors including TEM produced about 30 times more penicillinase in her strain of $P$. mirabilis than TEM in two different strains of this species studied here. Furthermore, one of the latter strains (F67) is the P. mirabilis of Rownd et al. (1966). It is not known whether this discrepancy can be attributed solely to strain differences.

Okamoto, Suzuki, Mise \& Nakaya (1967) found that the level of chloramphenicol inactivating enzyme was similar in Escherichia coli and in Proteus mirabilis. The R-factor 7268 studied here carries a $\mathrm{Cm}^{\mathrm{r}}$ allele and preliminary work has shown that it too mediates resistance by an inactivation mechanism. Moreover, the level of enzyme produced is similar in the same $E$. coli and $P$. mirabilis cells which show such marked differences in penicillinase levels. This it would seem that the cytoplasm of $P$. mirabilis can control some but not all R-factor gene functions. It is strange that although the work of Rownd et al. (1966) suggests that $P$. mirabilis cannot control the replication of its R-factors the work here suggests that they may partially compensate for this by controlling the phenotypic expression of some but not all R-factor genes.

I am particularly grateful for the expert technical assistance given by Miss $\mathbf{R}$. Anstey. I thank Dr Naomi Datta, Professor R. H. Gorrill, Dr J. M. T. HamiltonMiller, Professor W. Hayes and Dr F. Kauffman for sending bacterial strains. Much of this work was done at Guy's Hospital in Professor R. Knox's Department.

\section{REFERENCES}

ANDERson, E. S. \& DATTA, N. (1965). Resistance to penicillins and its transfer in Enterobacteriaceae. Lancet i, 407.

ANDERSON, E. S. \& LewIs, M. J. (1965). Drug resistance and its transfer in Salmonella typhimurium. Nature, Lond. 206, 579.

Clowes, R. C. \& RowLEY, D. (1954). Some observations on linkage effects in genetic recombination in Escherichia coli $\mathrm{K}$ 12. J. gen. Microbiol. $11,250$.

COHEN, M. \& Monod, J. (1957). Bacterial permeases. Bact. Rev. 21, I69.

CoLBY, C. \& HU, A. S. L. (1968). The regulation of the synthesis of $\beta$-galactosidase in Proteus mirabilis F-lac. Biochim. biophys. Acta 157, 149.

Datta, N. \& Kontomichalou, P. (1965). Penicillinase synthesis controlled by infectious R-factors in Enterobacteriaceae. Nature, Lond. 208, 239.

Davis, B. D. \& Mingioli, E. S. (1950). Mutants of Escherichia coli requiring methionine or vitamin B I 2. J. Bact. 60, 17.

Falkow, S., Citarella, R. V., Wohlhieter, J. A. \& Watanabe, T. (1966). The molecular nature of R-factors. J. molec. Biol. 17 , 102.

Falkow, S., Wohlhiteter, J. A., Citarella, R. V. \& Baron, L. S. (1963). Transfer of episomes to Proteus. Bact. Proc. p. 31.

Falkow, S., Wohlhieter, J. A., Citarella, R. V. \& Baron, L. S. (1964). Transfer of episomic elements to Proteus. I. Transfer of F-linked chromosomal determinants. J. Bact. 87, 209.

Heptinstall, R. H. \& GorRIL, R. H. (1955). Experimental pyelonephritis and its effect on the blood pressure. J. Path. Bact. 69, I9I.

JACOB, F. \& MONOD, J. (196I). Genetic regulatory mechanisms in the synthesis of proteins. J. molec. Biol. 3, 3 I8.

JACOB, F., BRENNER, S. \& CUZIN, F. (1963). On the regulation of DNA replication in bacteria. Cold Spring Harb. Symp. Quant. Biol. 28, 329.

Jacob, F., Schaeffer, P. \& Wollman, E. L. (1960). Episomic elements in bacteria. Symp. Soc. gen. Microbiol. 10, 67. 
Kontomichalou, P. (1967). Transmissible extrachromosomal resistance to the penicillins in $E$. coli $\mathrm{K} 12$ and Falkow's Proteus host. 5th int. Congr. Chemotherapy 4, 251.

Marmur, J., Rownd, R., Falkow, S., Baron, L. S., Schildkraut, C. \& Doty, P. (196i). The nature of intergenic episomal infection. Proc. natn. Acad. Sci., U.S.A. 47, 972.

MeYNELL, E. \& DATTA, N. (1966). The relation of resistance transfer factors to the F-factor (sexfactor) of Escherichia coli K12. Genet. Res. Camb. 7, 134.

Oxamoto, S., Suzuki, Y., Mise, K. \& NaKaYa, R. (1967). Occurrence of chloramphenicol-acetylating enzymes in various Gram-negative bacilli. J. Bact. 94, 1616.

RowND, R., NAKAYA, R. \& NAKAMURA, A. (1966). Molecular nature of the drug-resistance factors of the Enterobacteriaceae. J. molec. Biol. 17, 376.

Smrrh, J. T. (1963). Penicillinase and ampicillin resistance in a strain of Escherichia coli. J. gen. Microbiol. 30, 299.

Smrth, J. T. (1967). Production of thymineless mutants in Gram-negative bacteria (Aerobacter, Proteus). J. gen. Microbiol. 47, 131.

Smith, J. T. \& HAMILTON-MrLLER, J. M. T. (1963). Differences between penicillinases from Grampositive and Gram-negative bacteria. Nature, Lond. 197, 976.

Thompson, R. H.S. (1962). Classification and nomenclature of enzymes and coenzymes. Nature, Lond. $193,1227$.

WATANABE, T. (1963). Infective heredity of multiple drug resistance in bacteria. Bact. Rev. $27,87$.

Yoshikawa, H. \& Suzoka, N. (1963). Sequential replication of Bacillus subtilis chromosome. I. Comparison of marker frequencies in exponential and stationary growth phases. Proc. natn. Acad. Sci., U.S.A. 49, 559. 